\title{
A major barley allergen associated with baker's asthma disease is a glycosylated monomeric inhibitor of insect $\alpha$-amylase: cDNA cloning and chromosomal location of the gene
}

\author{
Montaña Mena, Rosa Sanchez-Monge, \\ Luis Gomez, Gabriel Salcedo and Pilar Carbonero
}

\begin{abstract}
A $14.5 \mathrm{kDa}$ barley endosperm protein that is a major allergen in baker's asthma disease, as previously shown by both in vitro (IgE binding) and in vivo tests, has been identified as a glycosylated monomeric member of the multigene family of inhibitors of $\alpha$-amylase/trypsin from cereals. A cDNA encoding this allergen (renamed BMAI-1) has been isolated and characterized. The deduced sequence for the mature protein, which is 132 residues long, is identical in its $\mathrm{N}$-terminal end to the 20 amino acid partial sequence previously determined from the purified allergen, and fully confirms that it is a member of the multigene family of cereal inhibitors. Southern-blot analysis of wheat/barley addition lines using the insert in the BMAI-1 cDNA clone as a probe, has led to the location of the allergen gene (Iam1) in barley chromosome 2, while another related member of this protein family, the barley dimeric $\alpha$-amylase inhibitor BDAI-1 gene (Iad1) has been located in chromosome 6. Iaml is the first member of this inhibitor family in cereals to be assigned to chromosome group 2, thus extending the dispersion of genes in the family to five out of the seven homology groups of chromosomes in wheat and barley (chromosomes $2,3,4,6$ and 7 ).
\end{abstract}

\section{Introduction}

A significant number of workers in the cereal industries that are exposed to inhalation of flours shows type I allergic responses mediated by $\operatorname{IgE}$ antibodies $[3,15,25]$. This allergy, named baker's asthma, is mainly provoked by flour proteins
[3]. Although a large number of these IgE-binding components has been detected in cereals, the most prominent allergens seem to be associated with the salt-soluble protein fraction $[1,2,5,24]$. The isolation and characterization of these allergens are an important goal in relation to the diagnosis and therapy of cereal allergies. In barley and

The nucleotide sequence data reported will appear in the EMBL, GenBank and DDBJ Nucleotide Sequence Databases under the accession number X63517 (H. vulgare Iam 1 gene). 
wheat most of the allergenic proteins characterized so far belong to the $\alpha$-amylase/trypsin inhibitor family $[4,7,11,13,20,27]$. This protein family accounts for a substantial fraction of the saltsoluble proteins of cereal endosperm and includes the $12-15 \mathrm{kDa}$ subunits of tetrameric, dimeric and monomeric inhibitors of heterologous $\alpha$ amylases and of trypsin [7, 8]. Most of these subunits are recognized by specific IgE antibodies when subjected to immunodetection with sera from allergic patients, but their IgE-binding affinities vary widely $[13,27]$. The three members of the family with the strongest in vitro and in vivo responses have been found to be the glycosylated form of a tetrameric inhibitor subunit from wheat (designated CM16*), the equivalent glycoprotein from barley $\left(\mathrm{CMb}^{*}\right)$ and a $14.5 \mathrm{kDa}$ allergen that is the most potent barley inhibitor of the $\alpha$-amylase from the storage pest Tenebrio molitor ([4, 27] and A. Armentia et al. submitted). Studies on the latter protein are therefore of interest both in connection with cereal allergies and in relation to plant protection. We report here on the cloning of its cDNA, the chromosomal location of the corresponding gene and the characterization of the inhibitor as a monomeric glycosylated protein (hereafter BMAI-1).

\section{Materials and methods}

\section{Biological material}

The cultivated barley Hordeum vulgare L. cv. Abissynian 2231 was the source of the poly $(\mathrm{A})^{+}$mRNA for the construction of the cDNA library. Barley cv. Bomi was used for protein purification. Disomic addition lines of Betzes barley in Chinese Spring wheat, kindly provided by K.W. Shepherd (Adelaide, Australia), were used for the chromosomal location of the genes.

\section{Screening of the cDNA library}

A cDNA library from immature barley endosperms in the vector $\lambda$ NM1149 was the gift of
W. Rohde (Max Planck Institute, Köln, FRG). The clones, blotted onto nylon filters (Hybond N, Amersham), were screened with a 23 nucleotide degenerate synthetic probe derived from the $\mathrm{N}$-terminal sequence of the purified allergen. This probe was ${ }^{32} \mathrm{P}$-labelled using $\mathrm{T}_{4}$-polynucleotide kinase, as described by Woods et al. [32]. Prehybridization was in $6 \times \mathrm{SSC}, 2 \times$ Denhardt's solution, $0.5 \%$ SDS, $100 \mu \mathrm{g} / \mathrm{ml}$ salmon sperm DNA at $42{ }^{\circ} \mathrm{C}$ for $4 \mathrm{~h}$. Hybridization was performed overnight at the same temperature. The filters were washed successively in $6 \times \mathrm{SSC}$ at $42{ }^{\circ} \mathrm{C}$ for $1 \mathrm{~h}$, at $49^{\circ} \mathrm{C}$ for $15 \mathrm{~min}$ and at $51^{\circ} \mathrm{C}$ for $15 \mathrm{~min}$. The last wash was in $6 \times \mathrm{SSC}, 0.5 \%$ sodium pyrophosphate.

Large-scale preparation of purified recombinant phages was carried out according to Yamamoto et al. [33].

\section{Nucleotide sequencing}

The complete sequence of the selected clone was determined by the dideoxy chain termination method [29]. An internal Sac I restriction site was used for producing the appropriate subclones. Both strands were sequenced. Sequencing reactions used as label $\left[\alpha-{ }^{35} \mathrm{~S}\right] \mathrm{dATP}(>1000 \mathrm{Ci} /$ mmol) and the products were separated on $8 \%$ polyacrylamide, $9 \mathrm{M}$ urea 'wedge' gels. Analysis and comparisons were performed with the Beckman Microgenie software and the EMBnet/CNB computer facilities.

Protein hydropathy and antigenicity profiles were obtained according to Hopp and Woods [16], and Jameson and Wolf [17].

\section{Southern blot analysis}

Total DNA was prepared from etiolated leaves of barley, wheat and wheat/barley addition lines after 7-10 days of germination. Tissue was ground to a powder under liquid $\mathrm{N}_{2}$ and extracted according to Murray and Thompson [23] with minor modifications. DNA was restricted with the appropriate endonucleases and separated on 
$0.75 \%$ agarose gels. Southern blotting was performed on nylon membranes (GeneScreen Plus, Dupont) following the manufacturer's instructions. The inserts of clones used as probes were

${ }^{32} \mathrm{P}$-labelled by the multiprime labelling system of Feinberg and Vogelstein [6]. Hybridizations were performed under stringent conditions by standard procedures [22].

\section{Purification of the allergen}

A crude $\alpha$-amylase/trypsin inhibitor preparation from Hordeum vulgare L. cv. Bomi endosperms was obtained by salt extraction as previously described $[4,14]$. The crude extract was size fractionated on Sephadex G-100 under non-dissociating conditions and the fractions corresponding to monomeric, dimeric and tetrameric inhibitors were pooled, dialysed and freeze-dried. The allergen was purified from the monomeric fraction (12-14 kDa) by preparative reverse-phase HPLC on an Ultrapore 300-5 C3 column (Beckman) using a three-step gradient of acetonitrile in $0.1 \%$ TFA (linear $10-20 \%$ in $45 \mathrm{~min} ; 20-35 \%$ in $140 \mathrm{~min} ; 35-50 \%$ in $100 \mathrm{~min} ; 1 \mathrm{ml} / \mathrm{min}$ ).

Protein electrophoresis, immunodetection and glycoprotein assay

SDS-PAGE and two-dimensional gel electrophoresis were carried out as described $[14,19]$.

A pool of sera from patients with baker's asthma was used for immunodetection. All sera were RAST (radioallergosorbent test) class 3 or 4 when assayed with commercial wheat flour discs (Phadebas-RAST Kit, Pharmacia). After SDSPAGE the gel was soaked for 15 min in transfer buffer ( $50 \mathrm{mM}$ Tris, $50 \mathrm{mM}$ boric acid $\mathrm{pH} 8.3$ ) and then electrotransferred to PVDF membranes (Immobilon, Millipore) for $60 \mathrm{~min}$ at $100 \mathrm{~V}$. The membranes were treated with $1: 3$ serum dilutions and anti-human $\operatorname{IgE}{ }^{125}$ I-labelled as described by Lunghtenberg et al. [21].

Membrane-bound proteins were alternatively stained for conjugated carbohydrates according to Gershoni et al. [12] with minor modifications. Membranes treated with $10 \mathrm{mM}$ periodic acid and rinsed with water until neutrality were dipped in $1 \%(\mathrm{w} / \mathrm{v})$ dansylhydrazine in ethanol to which $0.2 \mathrm{M}$ sodium acetate $(\mathrm{pH} 5.4)$ was added. After incubation in the dark ( $30 \mathrm{~min}$ ), the reagents were discarded, and the membrane washed successively with water, $0.2 \mathrm{M}$ sodium acetate and $50 \%$ methanol. Glycoproteins were visible under UV light.

\section{Results}

Characterization of a $c D N A$ clone encoding the allergen BMAI-1

A cDNA library derived from barley endosperm at 14 days after pollination (dap) was screened with a 23 nucleotide mixed probe $\left(5^{\prime} \mathrm{GAA} /\right.$ GTGGTGC/TTGGCCXGGXATGGG-3') deduced from positions 4 to 11 of the known $\mathrm{N}$ terminal amino acid sequence of BMAI-1 [4]. One clone with an insert of approximately $600 \mathrm{bp}$, designated $\lambda \mathrm{AL} 1$, was selected because it hybridized with the oligonucleotide probe and it did not cross-hybridize, under stringent conditions, with the insert in clone pUP44, corresponding to protein BDAI-1, an homologous barley dimeric $\alpha$ amylase inhibitor [20]. The nucleotide sequence of the insert in clone $\lambda \mathrm{AL} 1$, which appears in Fig. 1, corroborated its homology to the oligonucleotide probe and the amino acid sequence deduced from its longest open-reading frame, includes the known $20 \mathrm{~N}$-terminal residues directly determined in the purified allergen from barley endosperm [4]. The deduced mature protein of 132 amino acids is preceded by a putative truncated signal peptide of 14 amino acids. This latter sequence has $50 \%$ coincident positions with the signal peptide of the wheat monomeric $\alpha$-amylase inhibitor WMAI-1 [10].

In Fig. 2, the deduced amino acid sequence of the allergen (BMAI-1) has been aligned with the sequences of BDAI-1 and WMAI-1, which are closely related members of the same multigene family $[9,18,20]$. Putative $\mathrm{N}$-glycosylation sites 


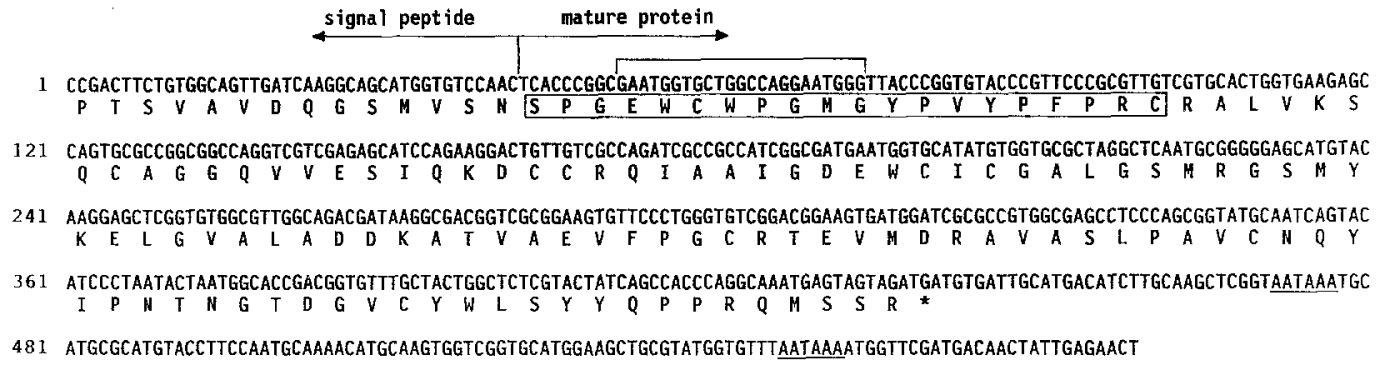

Fig. 1. Nucleotide sequence and deduced amino acid sequence of insert in clone $\lambda$ AL1, which corresponds to the major barley allergen associated with baker's asthma (BMAI-1). The sequence identical to the known N-terminal sequence of the purified allergen [4] is boxed. A bracket spans the region hybridizing with the oligonucleotide probe used in the screening of the cDNA library. The AATAAA polyadenylation signals are underlined. The stop codon is indicated with an asterisk.

(NXS/T) in the three sequences are underlined. The homology among these three proteins is evident as the positions of the 10 cysteines are absolutely conserved and the overall similarity values (matches/length) of the allergen compared to BDAI- 1 and WMAI- 1 are $57 \%$ and $59 \%$ respectively.

Prediction of antigenic domains for the deduced amino acid sequence of the allergen BMAI-1 is presented in Fig. 3 together with those corresponding to BDAI-1 and WMAI-1. Antigenic indexes $>1.7$ predominate around the putative $\mathrm{N}$-glycosylation sites both in BMAI-1 and WMAI-1, while in BDAI-1 there is a zone with such characteristics around the $\mathrm{C}$-terminal end of the molecule.

\section{Chromosomal location of the gene Iam-1}

To locate the gene encoding BMAI-1, designated Iam-1, the insert in clone $\lambda \mathrm{AL} 1$ was used as a probe for the Southern analysis of the DNAs from the wheat/barley addition lines. Only the addition line corresponding to barley chromosome 2 showed a band of ca. $3.4 \mathrm{~kb}$ that also appeared in the barley cultivar Bétzès from which these lines have been derived. This band was absent in the receptor wheat Chinese Spring (Fig. 4A). Similarly, gene Iad-1 encoding BDAI1 , which had not been previously located, was found to be in barley chromosome 6 (Fig. 4B) using the insert in its corresponding clone pUP44 $[20]$ as a probe.

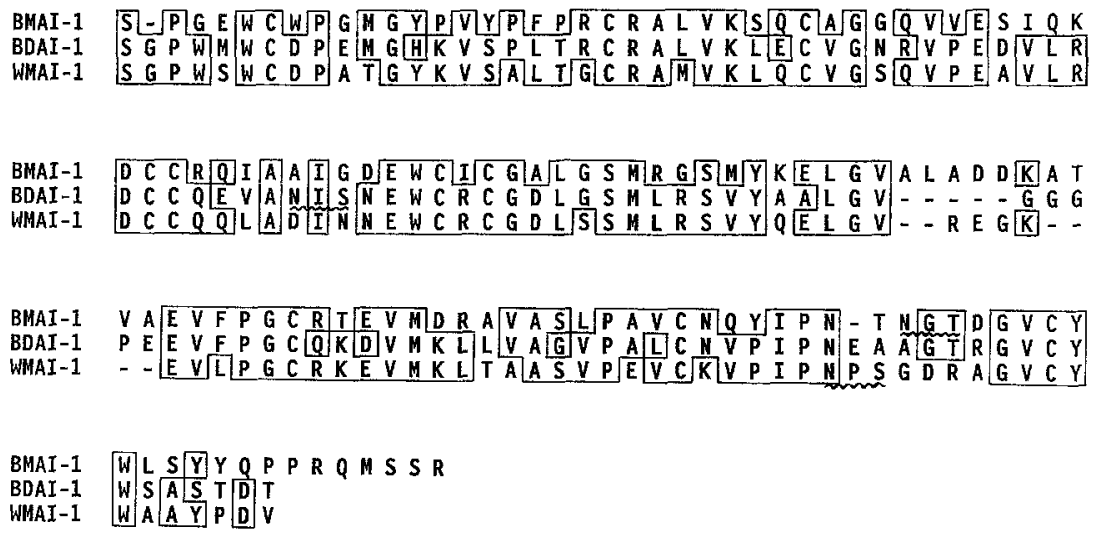

Fig. 2. Alignment of the sequence deduced from clone $\lambda \mathrm{AL} 1$ with related members of the same protein family: BDAI-1, a barley homodimeric $\alpha$-amylase inhibitor [20], and WMAI-1, a wheat monomeric $\alpha$-amylase inhibitor $[9,18]$. Identical residues at a given position are boxed. Putative N-glycosylation sites (NXS/T) are underlined with a wavy line. 


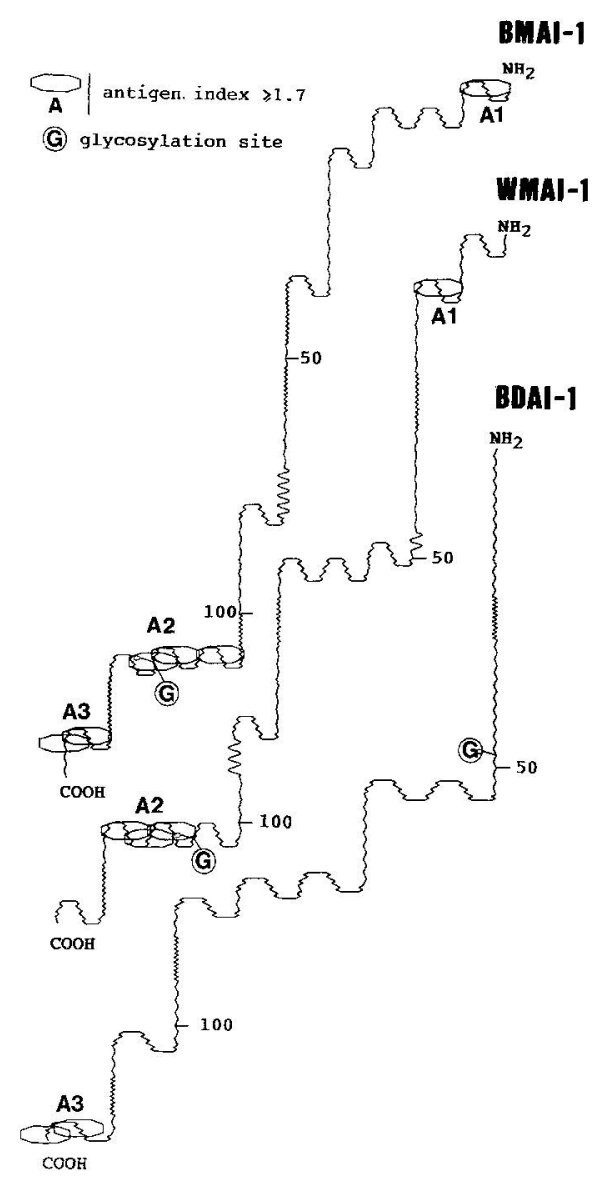

Fig. 3. Antigenicity profiles according to Jameson and Wolf [17] for proteins BMAI-1, WMAI-1 and BDAI-1.
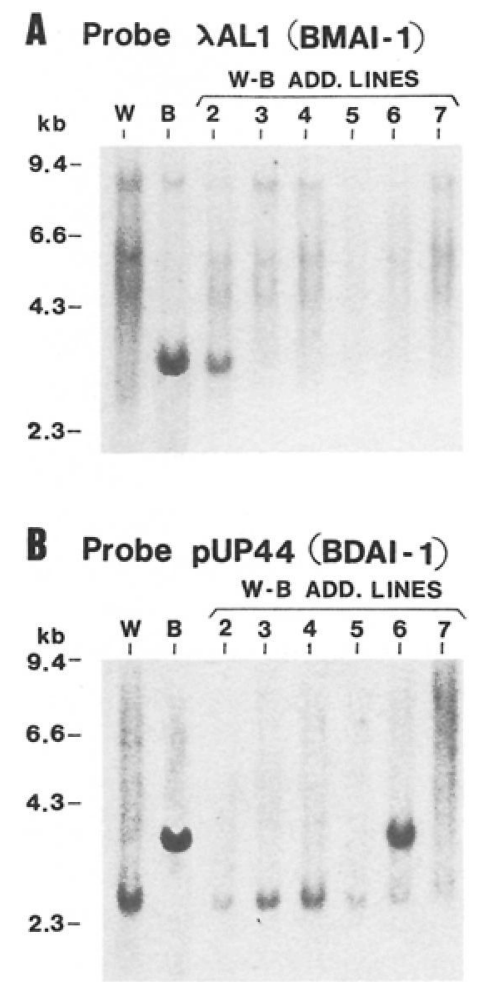

Fig. 4. Chromosomal location of genes corresponding to the allergen BMAI- 1 and to BDAI-1. Southern blot hybridization of the following genotypes: hexaploid wheat, Triticum aestivum cv. Chinese Spring (W); diploid barley, Hordeum vulgare cv. Bétzès (B); Chinese Spring wheat/Betzes barley addition lines $(2,3,4,5,6,7)$. DNA digested with restriction endonuclease Hind III was first hybridized with the insert in clone $\lambda \mathrm{AL} 1$ (A) corresponding to BMAI-1, and then, after washing off this probe, with the insert in clone pUP44 (B) corresponding to BDAI-1 [20].
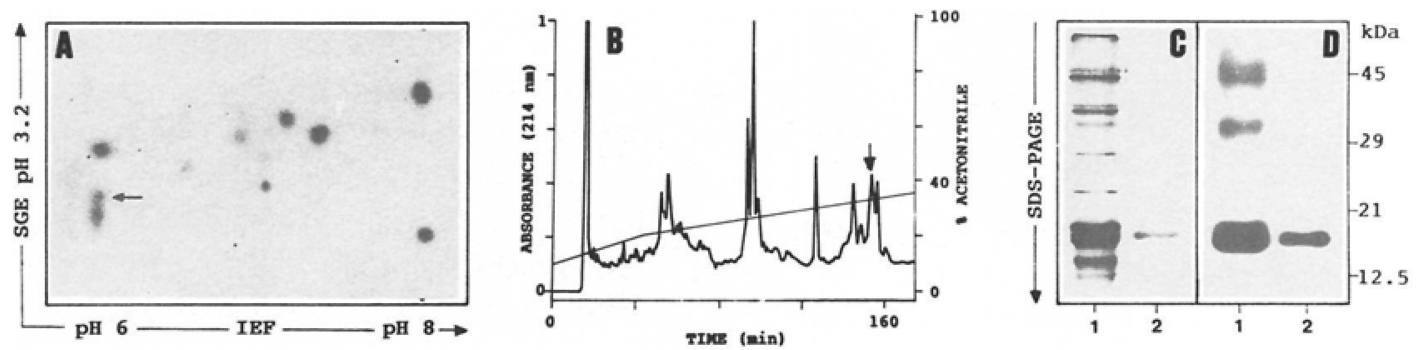

Fig. 5. Purification of the allergen BMAI-1 from the gel filtration fraction corresponding to the monomeric inhibitors of $\alpha$-amylase/ trypsin. A. Two-dimensional electrophoresis (isoelectric focusing pH 6-8 $\times$ starch gel electrophoresis pH 3.2) of the monomeric peak of inhibitors from barley endosperms. B. HPLC fractionation of the same extract. The arrows point to the position of BMAI-1. C, D. SDS-PAGE of the crude inhibitor preparation from bariey endosperms (1) and HPLC-purified allergen BMAI-1 (2). C. Coomassie Blue staining. D. Immunoblot of a replica of the gel in $\mathrm{C}$, treated with a pool of sera from baker's asthma patients and ${ }^{125}$ I-labelled anti-human IgE. 
Evidence that BMAI-1 is monomeric and glycosylated

A crude inhibitor preparation from barley was subjected to gel filtration on Sephadex G-100 and the fractions corresponding to monomeric, dimeric and tetrameric inhibitors were recovered as previously described $[14,28]$. Protein BMAI-1 was identified in the monomeric fraction both by two-dimensional (2D) gel electrophoresis (Fig. 5A) and by preparative HPLC (Fig. 5B). The allergenic properties of BMAI-1 isolated from the monomeric fraction were checked following SDS-PAGE and electrotransfer to a PVDF membrane by reaction with pooled sera from patients suffering from baker's asthma (Figs. 5C, D).

Purified BMAI-1 was also separated by SDSPAGE in parallel with glycosylated $\left(\mathrm{CMb}^{*}\right)$ and non-glycosylated (WMAI-1, BDAI-1) members of the inhibitor family, as well as with transferrin and chymotrypsinogen as positive and negative controls respectively. The gel was specifically stained for glycoproteins with dansylhydrazine after periodic oxidation (Fig. 6). Protein BMAI1 gave a positive reaction together with $\mathrm{CMb}^{*}$ and transferrin, while WMAI-1, BDAI-1 and chymotrypsinogen did not.

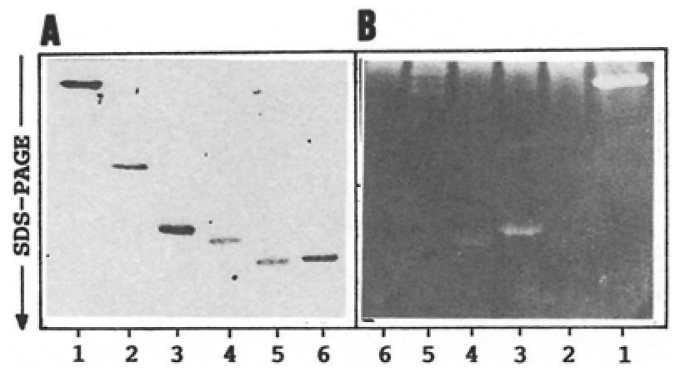

Fig. 6. Glycoprotein staining (B) according to Gershoni et al. [12] after SDS-PAGE (A) of the following members of the family of inhibitors of $\alpha$-amylase/trypsin: subunit $\mathrm{CMb}^{*}$ from the barley tetrameric $\alpha$-amylase inhibitor (3), the allergen BMAI-1 (4), the barley homodimeric inhibitor BDAI-1 (5) and the wheat monomeric inhibitor WMAI-1 (6). Transferrin (1) and chymotrypsinogen (2) were used as positive and negative controls respectively.

\section{Discussion}

The deduced amino acid sequence of protein BMAI-1 confirms that it corresponds to the $14.5 \mathrm{kD}$ a allergen previously associated with baker's asthma [4], and that it is a member of the same protein family as the monomeric, dimeric and tetrameric inhibitors of $\alpha$-amylase and of trypsin from cereals. Furthermore, the sequence of BMAI-1 is closer to those of monomeric and dimeric inhibitors, such as BDAI-1 and WMAI-1 (ca. $60 \%$ identical residues) than to any of the other proteins of this multigene family (20-45\% identical residues), such as the trypsin inhibitors and the subunits of the tetrameric inhibitors of $\alpha$-amylase [7, 8, 11, 26].

Concerning the in vitro $\alpha$-amylase inhibitory properties of BMAI-1 and WMAI-1, as well as those of the homodimeric barley inhibitor BDAI1 , we have previously shown that they are at least one order of magnitude greater towards the insect Tenebrio molitor $\alpha$-amylase than against the human salivary enzyme, whereas the three wheat dimeric inhibitors characterized so far are more active against the human salivary $\alpha$-amylase than against the $T$. molitor enzyme [8].

Genes encoding monomeric inhibitors in wheat are located in chromosomes of homology group 6, while those corresponding to wheat dimeric inhibitors are in chromosomes of homology group 3 [8]. Genes Iaml and Iadl, corresponding to BMAI-1 and BDAI-1, respectively, have been assigned in the present report to chromosomes 2 and 6 , respectively.

All these data concerning sequence homology, in vitro $\alpha$-amylase specificity, and genetic control, suggest that barley loci Iaml and Iadl have diverged from a monomeric-type ancestral gene and that BDAI- 1 acquired the ability to self-associate into dimers, without changing its specificity or chromosomal location, whereas BMAI-1 retained both its monomeric nature and its specificity but its gene was translocated to a new position in chromosome 2. Although evidence of translocation events between rye chromosomes 2 and 6 have been reported [30], to our knowledge this is the first report concerning such an event between 
chromosomes 2 and 6 in barley. Moreover, the BMAI-1 gene is the first member of this multigene family of inhibitors to be assigned to chromosome 2, thus extending to 5 out of the 7 homology groups, the distribution of genes in this disperse family (chromosomes 2, 3, 4, 6 and 7) where gene duplications and translocations are frequently observed [8].

BMAI-1, BDAI-1 and WMAI-1, all have in their sequences one putative $\mathrm{N}$-glycosylation site (NXS/T), while only BMAI-1 is actually glycosylated (Fig. 6). Moreover, protein BMAI-1 has three predicted domains of high antigenicity index (n>1.7): $\mathrm{A}_{1}, \mathrm{~A}_{2}, \mathrm{~A}_{3}$ (Fig. 3), while proteins WMAI-1 and BDAI-1 have two $\left(\mathrm{A}_{1}, \mathrm{~A}_{2}\right)$ and one $\left(\mathrm{A}_{3}\right)$ shorter predicted antigenic domains, respectively, and are not glycosylated (Fig. 6). The glycosylation and high antigenicity profile of BMAI-1 are in agreement with its known allergenic properties and IgE binding capacity: BMAI- $1>>$ BDAI- $\approx$ WMAI- 1 . The other major barley allergen associated with baker's asthma, $\mathrm{CMb}^{*}$, is also glycosylated [27].

Finally, the cDNA clone for this barley allergen can be a useful tool for epitope mapping through site-directed mutagenesis in bacterial expression systems, and can be of advantage over the peptide synthesis method for epitope mapping proposed by Walsh and Bowden [31]. Moreover, its expression in transgenic plants can be of biotechnological interest in crop protection.

The technical assistance of L. Lamoneda and J. García is acknowledged. We thank Professor F. García-Olmedo for helpful discussions and critical reading of the manuscript. This work was financed by grants Bio91-0782 and Ali89-0121 from Comision Interministerial de Ciencia y Tecnología (Spain).

\section{References}

Baldo BA, Krilis S, Wrigley CW: Hypersensitivity to inhaled flour allergens. Comparison between cereals. Allergy 35: 45-56 (1980).
Baldo BA, Wrigley CW: IgE antibodies to wheat flour components. Studies with sera from patients with baker's asthma and coeliac conditions. Clin Allergy 8: 109-124 (1978).

Baldo BA, Wrigley CW: Allergies to cereals. Adv Cereal Sci Technol 6: 289-356 (1984).

Barber D, Sanchez-Monge R, Gomez L, Carpizo J, Armentia A, Lopez-Otin C, Juan F, Salcedo G: A barley flour inhibitor of insect $\alpha$-amylase is a major allergen associated with baker's asthma disease. FEBS Lett 248: 119-122 (1989).

Blands J, Diamant W, Kallos-Deffner L, Lowenstein H: Flour allergy in bakers. Int Arch Allergy Appl Immunol 52: 392-406 (1976).

Feinberg AP, Vogelstein B: A technique for radiolabeling DNA restriction endonuclease fragments to high specific activity. Anal Biochem 132: 6-13 (1983).

García-Olmedo F, Salcedo G, Sanchez-Monge R, Gomez L, Royo J, Carbonero P: Plant proteinaceous inhibitors of proteinases and $\alpha$-amylases. Oxford Surv Plant Mol Cell Biol 4: 275-334 (1987).

García-Olmedo F, Salcedo G, Sanchez-Monge R, Hernández-Lucas C, Carmona MJ, Lopez-Fando JJ, Fernandez JA, Gomez L, Royo J, García-Maroto F, Castagnaro A, Carbonero P: Alpha-amylase/trypsin inhibitors and thionins. Possible defence proteins from barley. In Shewry PR (ed), Barley: Genetics, Molecular Biology and Biotechnology, pp. 335-350. CAB International, Wallingford (1992).

García-Maroto F, Carbonero P, García-Olmedo F: Site-directed mutagenesis and expression in Escherichia coli of WMAI-1, a wheat monomeric inhibitor of insect $\alpha$-amylase. Plant Mol Biol 17: 1005-1011 (1991).

García-Maroto F, Castagnaro A, Sanchez de la $\mathrm{Hoz} \mathbf{P}$, Maraña C, Carbonero P, García-Olmedo F: Extreme variations in the ratios of non-synonymous to synonymous nucleotide substitution rates in signal peptide evolution. FEBS Lett 287: 67-70 (1991).

García-Maroto F, Maraña C, Mena M, García-Olmedo F, Carbonero P: Cloning of cDNA and chromosomal location of genes encoding the three types of subunits of the wheat tetrameric inhibitor of insect $\alpha$-amylase. Plant Mol Biol 14: 845-853 (1990).

Gershoni JM, Bayer EA, Wilchek M: Blot analyses of glycoconjugates: enzyme-hydrazide, a novel reagent for the detection of aldehydes. Anal Biochem 146: 59-63 (1985).

Gomez L, Martin E, Hernandez D, Sanchez-Monge R, Barber D, Pozo V, Andres B, Armentia A, Lahoz C, Salcedo $G$, Palomino P: Members of the $\alpha$-amylase inhibitors family from wheat endosperm are major allergens associated with baker's asthma. FEBS Lett 261: 85-88 (1990).

Gomez L, Sanchez-Monge R, García-Olmedo F, Salcedo G: Wheat tetrameric inhibitors of insect $\alpha$-amylase: 
alloploid heterosis at the molecular level. Proc Natl Acad Sci USA 86: 3242-3246 (1989).

Hendrich DJ, Davies RJ, Pepys J: Baker's asthma, immediate and late reactions. Clin Allergy 6: 241-250 (1976).

Hopp TP, Woods KR: Prediction of protein antigenic determinants from amino acid sequences. Proc Natl Acad Sci USA 78: 3824-3828 (1981).

Jameson BA, Wolf $\mathrm{H}$ : The antigenic index: a novel algorithm for predicting antigenic determinants. CABIOS 4 : 181-186 (1988).

Kashlan N, Richardson M: The complete amino acid sequence of a major wheat protein inhibitor of $\alpha$-amylase. Phytochemistry 20: 1781-1784 (1981).

Laemmli UK: Cleavage of structural proteins during the assembly of the head of bacteriophage T4. Nature 227 : 680-685 (1970).

Lazaro A, Sanchez-Monge R, Salcedo G, Paz-Ares J, Carbonero P, García-Olmedo F: A dimeric inhibitor of insect $\alpha$-amylase from barley. Cloning of the CDNA and identification of the protein. FEBS Lett 172: 129-134 (1988).

Lughtenberg B, Meijers J, Peters R, van der Hoek P, van Alphen I: Electrophoretic resolution of the major outer membrane of Escherichia coli K12 into four bands. FEBS Lett 58: 254-258 (1975).

Maniatis T, Fritsch EF, Sambrook J: Molecular Cloning: A Laboratory Manual. Cold Spring Harbor Laboratory, Cold Spring Harbor, NY (1982).

Murray MG, Thompson WF: Rapid isolation of high molecular weight plant DNA. Nucl Acids Res 8: 43214325 (1980).

Pfeil T, Schwabl U, Ulmer WT, König W: Western blot analysis of water-soluble wheat flour (Triticum vulgaris) allergens. Int Arch Allergy Appl Immunol 91: 224-231 (1990).

Popa V, George SA, Gavanescu O: Occupational and non-occupational respiratory allergy in bakers. Acta Allergol 25: 159-177 (1970).

Rodriguez-Palenzuela P, Royo J, Gomez L, SanchezMonge R, Salcedo G, Molina-Cano JL, García-Olmedo $\mathrm{F}$, Carbonero P: The gene for trypsin inhibitor $\mathrm{CMe}$ is regulated in trans by the lys 3 a locus in the endosperm of barley (Hordeum vulgare L). Mol Gen Genet 219: 474479 (1989).

Sanchez-Monge R, Gomez L, Barber D, Lopez-Otin C, Armentia A, Salcedo G: Wheat and barley allergens associated with baker's asthma: glycosylated subunits of the $\alpha$-amylase inhibitors family have enhanced IgE-binding capacity. Biochem J 281: 401-405 (1992).

Sanchez-Monge R, Gomez L, García-Olmedo F, Salcedo G: A tetrameric inhibitor of insect $\alpha$-amylase from barley. FEBS Lett 207: 105-109 (1986).

Sanger F, Nicklen S, Coulson AR: DNA sequencing with chain terminating inhibitors. Proc Natl Acad Sci USA 74: 5463-5467 (1977).

Shewry PR, Parmar S, Miller TE: Chromosomal location of the structural genes for the Mr $75000 \tau$-secalins in Secale montanum Guss: evidence for a translocation involving chromosomes $2 \mathrm{R}$ and $6 \mathrm{R}$ in cultivated rye (Secale cereale L.). Heredity 54: 381-383 (1985).

Walsh BJ, Bowden MEH: A method for the detection of IgE binding sequences of allergens based on a modification of epitope mapping. J Immun Meth 121: 275-280 (1989).

Woods DE, Markham AF, Ricker AT, Goldberg G, Cotten HR: Isolation of cDNA clones for the human complement protein factor $B$, a class III major histocompatibility complex gene product. Proc Natl Acad Sci USA 79: 5661-5665 (1982).

Yamamoto KR, Alberts BM, Benzinger R, Lawhorne L, Treiber G: Rapid bacteriophage sedimentation in the presence of polyethylene glycol and its application to large scale virus purification. Virology 40: 7434-7439 (1970). 